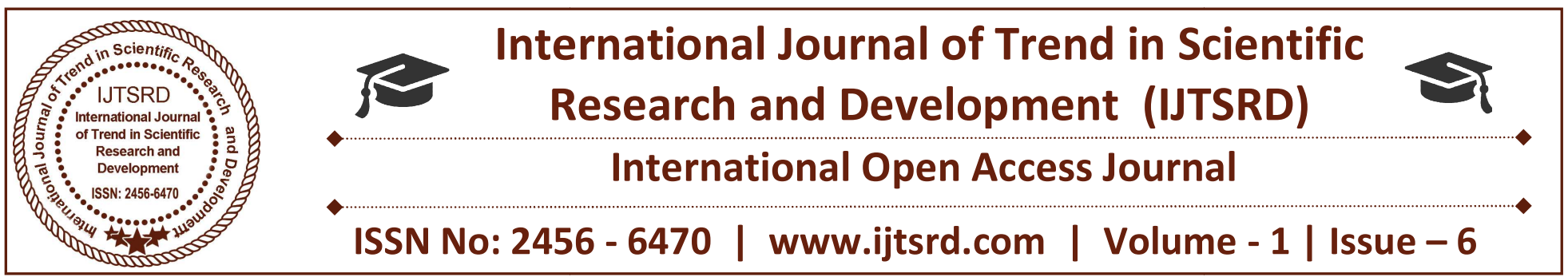

\title{
Optimization of Machiining Parameters in Turning Operation of Aluminium Alloy for Surface Temperature
}

\author{
Abhishek Kumar \\ Research Scholar Specialization in Industrial \& \\ Production Engineering
}

\author{
Mr. Deepak Gaur \\ Assistant Professor (MED), JMIT, Radaur
}

\begin{abstract}
The adjustment in properties of any metal relies on temperature rise during the machining operations. Temperature rise change with various parameters, for example, cutting speed, feed, and depth of cut. It has been uncovered that great deals of endeavors have been done in various turning. However, a little work has been done in turning for temperature rise. The work is performed for better machining operation which can be utilized for quality control of machining parts. This will help to concerned $\mathrm{R}$ and $\mathrm{D}$ analysts or mechanical specialists by providing database.
\end{abstract}

First pilot experiments were done on the work piece using random values and then from those pilot experiments the suitable values of these parameters were selected. On the basis of observations from the pilot experiments four values of Spindle speed $59,118,165,220$, four values of feed $.12, .14, .16, .18$ and four values of Depth of cut .8, 1, 1.2, 1.4 were chosen. L16 orthogonal array performed using these values.

It is concluded that for Temperature to be minimum Cutting speed has to be at high level 4, Feed has to be at low level 1 \& D.O.C has to be at level 2.

Keywords: Machining, Taguchi, Orthogonal Array, Signal to noise ratio

\section{INTRODUCTION}

Turning metal removal is the removal of metal outside diameter of a rotating cylindrical work piece. As it is used to reduce the diameter of the work piece generally to a specified dimension and to produce a smooth finish on the metal. Often, the workpiece is turned so that the sections have different diameters.

As is the machining operation that produces cylindrical. In its basic form, it can be defined as an outer surface machining:

$>$ With the rotation of the workpiece.

$>$ With the help of the cutting tool of a single point.

$>$ With the power cutter parallel to the axis of the work piece to remove the outer surface of the work.

For years, quality and productivity have been seen as two important indices of Taper is practically the same, except that the way the blade is at an angle with respect to the working axis. Similarly, in the turning contour, the distance of the blade from the working axis is changed to produce the desired shape. Although specified tool a single point, this does not preclude implementing multiple tool, which often are used in transformation. In such configurations, each tool operates independently as a cutting tool of a single point.

The adjustment in properties of any metal relies on temperature rise during the machining operations. Temperature rise change with various parameters, for example, cutting speed, feed, depth of cut. It has been uncovered that a great deal of endeavors has been done in various turning. However, a little work has been done in turning for temperature rise. The work is performed for better machining operation which can be utilized for quality control of machining parts. This 
will help to concerned $\mathrm{R}$ and $\mathrm{D}$ analysts or mechanical specialists by providing database.

\section{Literature Study}

Buddy and Chakraborty (2005) [1] concentrated to build up a model of neural system back-engendering for forecast of surface harshness in turning operation and is utilized mellow steel workpieces with rapid steel as the removing device to convey various tests. The creators utilized speed, encourage, profundity of cut and slicing powers as contributions to the neural system show for forecast of surface unpleasantness. The work brought about the planned surface unpleasantness was near the exploratory esteem.

Sing and Kumar (2006) [2] contemplated the streamlining of the encourage constrain through ideal modification of process parameters to be specific speed, bolster and profundity of cut in steel preparing with carbide embeds EN24 TiC covered tungsten. The creators utilized the approach Taguchi outline parameters and presumed that the impact of sustain and cutting profundity variety in nourish constrain influenced more when contrasted with the speed.

Ahmed (2006) [3] built up the philosophy for getting the ideal procedure parameters for expectation of surface unpleasantness in turning Al. To build up the exact model nonlinear relapse investigation with logarithmic change of information it was connected. The model created demonstrated little oversights and agreeable outcomes. The investigation presumed that low bolster rate regarded create low surface harshness and rapid could produce high surface quality inside the trial space.

Abburi and Dixit (2006) [4] they created in view of information for foreseeing surface harshness in turning process framework. Fluffy set hypothesis and neural systems were utilized for this reason. The creators created lead to anticipate the surface unpleasantness for the procedure factors and for the expectation of process factors for a given surface harshness.

Zhong et al. (2006) [5] anticipated the surface harshness of machined surfaces utilizing nets with seven innings to be specific degree addition instrument, workpiece materials, front line range, point, profundity of cut, axle speed and bolster rate .
Kumanan et al. (2006) [6] proposed an approach for foreseeing the machining powers utilizing multilayer perceptron prepared by hereditary calculation (GA). The information acquired from test aftereffects of a turning procedure is investigated to prepare counterfeit neural systems proposed (RNAs) with three contributions for yield machining powers. ANN ideal weights were gotten utilizing GA look. This half and half capacity supplanting made of GA and ANN discovered computationally effective and exact to anticipate the powers of machining for the machining states of passage.

Mahmoud and Abdelkarim (2006) [7] considered in turning operation utilizing fast steel (HSS) cutting apparatus 450 at an edge of approach. This instrument demonstrated he could complete the cutting operation at higher rates and longer administration life of the customary device with a rake point of 90 degrees. The examination eventually decides the ideal cutting rate for high creation speed and least cost and instrument, generation time and working expenses.

Doniavi et al. (2007) [8] utilizing the reaction surface approach (RSM) keeping in mind the end goal to build up the observational model for the forecast of surface harshness, in choosing the ideal cutting condition in the change. The creators demonstrated that the encourage rate fundamentally affected surface unpleasantness. With expanded surface unpleasantness speed control was observed to be expanded. With the expansion in the cutting pace diminished surface unpleasantness. Examination of difference demonstrated that the impact of the nourish rate and were in surface unpleasantness of the cutting profundity was connected.

Kassab and Khoshnaw (2007) [9] inspected the connection between's surface unpleasantness and vibration cutting instrument for turning operations. The procedure parameters were cutting pace, profundity of cut, encourage rate and extraordinary apparatus. The trials were completed on the machine turning utilizing dry (without cutting liquid) operation of medium carbon steel with various levels of process parameters specified previously. Turning was dry helpful for a decent relationship between's the surface harshness and the cutting device vibration due clean condition. The creators built up a decent connection between's the vibration slicing instrument surface harshness and to control the surface complete of the workpieces amid large scale manufacturing. The 
examination presumed that it was watched that the surface harshness of the workpiece to be influenced more by the speeding up cutting instrument; quickening expanded shade of the cutting apparatus. The surface unpleasantness was found to increment with expanding encourage rate.

Al-Ahmari (2007) [10] created experimental models for the apparatus life, surface harshness and cutting power for turning operation. The procedure parameters were utilized as a part of the investigation speed, nourish, profundity of slice and the nose range to build up the model machining. The strategies used to create 48 models specified above were Response Surface Methodology (RSM) and neural systems $(\mathrm{NN})$.

Thamizhmanii et al. (2007) [11] connected the Taguchi technique to locate the ideal estimation of the harshness of the surface under ideal cutting conditions in turning SCM 440 combination steel. The analysis was outlined utilizing the Taguchi strategy.

Natarajan et al. (2007) [12] presented the procedure of checking apparatus wear web based handling operation. Shaft speed, bolster, cutting profundity, cutting power, control axle engine and temperature were chosen as the information parameters for the observing procedure. To decide the level of wear of the instrument; Two techniques for Hidden Markov Model (HMM) strategy, for example, visual chart and different displaying strategies were utilized. A calculation of choice combination focus (DFCA) was utilized to build the dependability of this yield consolidates the yields of the individual techniques to settle on a complete choice on the wear of the device. At last, all the proposed strategies were consolidated in a DFCA to decide the wear of the device amid turning operations.

\section{Problem formulation \& Methodology}

The steps covered in Methodology are as follows:

\section{Determine the quality characteristic to be optimized}

Taguchi Method is the first step in determining the quality characteristics to be optimized. Appearance quality parameters are changed to have a significant impact on the quality of the product. It is different to export or responses are observed.

\section{Identify the noise factors and test conditions}

The next step is to identify risk factors that can affect system performance and quality. This parameter is the noise factor cannot control either over or expensive to control. Noise factors, including changes in operating conditions, environmental deterioration of parts that are in use and changes in responses between the products of the same design with the same input.

\section{Identify the control parameters and their alternative levels}

The third step is to identify the control parameters are thought to be affected significantly $\mathrm{n}$ nature, quality control (test) parameters are design factors that can be set up and maintenance level (the test). For each test parameter must be appointed to this point.

\section{Design the matrix experiment and define the data analysis procedure}

The next step is to design an experimental matrix and procedures for data analysis. The first scene suitable for an array of audio and control parameters to fit specific studies have been selected. There are several standard Taguchi linear array perpendicular and corresponding graphs for the purpose of the day. After selecting the appropriate steps array to simulate the change in quality due to noise characteristics to be determined. How common is the use of simulation Monte Carlo, however, for assessing the accuracy of the mean and variance Monte Carlo simulation requires a lot of test conditions, which can be expensive and time-consuming way. Taguchi array choose the model proposed by evaluating the mean and variance of responses caused by product model, the risk factors.

\section{Conduct the matrix experiment}

The next step is to conduct experimental matrix and the Taguchi method can be used in any situation in the event of process control. The current process control system hardware test mathematical or computer models that can adequately respond to patterns of many products and processes.

\section{Analyze the data and determine the optimum levels for control factors}

After the test has been conducted to determine the parameters of the best trial design must be considered. Taguchi method is used to analyze the statistical 
International Journal of Trend in Scientific Research and Development (IJTSRD) ISSN: 2456-6470 measures of performance known as the signal-noise control. $(\mathrm{S} / \mathrm{N})$ ratio theory borrowed from the electric

\section{Results and Discussions:}

\subsection{Calculation of Temperature}

The results of the test are shown in the observation table below. The Signal to noise ratio minimum is better for all runs of Surface Temp. Are shown in following table:-

\section{Table 1: Calculation of Temperature}

\begin{tabular}{|c|c|c|c|c|c|c|}
\hline Sr. No. & RPM & FEED & D.O.C & TEMP $\left({ }^{\circ} \mathrm{C}\right)$ & SNRA1 & MEAN1 \\
\hline 1 & 59 & 0.12 & 0.8 & 34.1 & -30.6551 & 34.1 \\
\hline 2 & 59 & 0.14 & 1 & 32.2 & -30.1571 & 32.2 \\
\hline 3 & 59 & 0.16 & 1.2 & 33.4 & -30.4749 & 33.4 \\
\hline 4 & 59 & 0.18 & 1.4 & 33.1 & -30.3966 & 33.1 \\
\hline 5 & 118 & 0.12 & 1 & 30.6 & -29.7144 & 30.6 \\
\hline 6 & 118 & 0.14 & 0.8 & 33.7 & -30.5526 & 33.7 \\
\hline 7 & 118 & 0.16 & 1.4 & 32.6 & -30.2644 & 32.6 \\
\hline 8 & 118 & 0.18 & 1.2 & 30.4 & -29.6575 & 30.4 \\
\hline 9 & 165 & 0.12 & 1.2 & 30.4 & -29.6575 & 30.4 \\
\hline 10 & 165 & 0.14 & 1.4 & 30.8 & -29.771 & 30.8 \\
\hline 11 & 165 & 0.16 & 0.8 & 34.2 & -30.6805 & 34.2 \\
\hline 12 & 165 & 0.18 & 1 & 31.1 & -29.8552 & 31.1 \\
\hline 13 & 220 & 0.12 & 1.4 & 31.5 & -29.9662 & 31.5 \\
\hline 14 & 220 & 0.14 & 1.2 & 31.5 & -29.9662 & 31.5 \\
\hline 15 & 220 & 0.16 & 1 & 31.7 & -30.0212 & 31.7 \\
\hline 16 & 220 & 0.18 & 0.8 & 32 & -30.103 & 32 \\
\hline
\end{tabular}

\section{Linear Model Analysis for Surface Temp:}

\section{Table 2:_Surface Temp. Response Table for Signal}

\section{to Noise Ratios}

Smaller is better

\begin{tabular}{|l|l|l|l|}
\hline Level & RPM & FEED & D.O.C \\
\hline 1 & -30.42 & -30.00 & -30.50 \\
\hline 2 & -30.05 & -30.11 & -29.94 \\
\hline 3 & -29.99 & -30.36 & -29.94 \\
\hline 4 & -30.01 & -30.00 & -30.10 \\
\hline Delta & 0.43 & 0.36 & 0.56 \\
\hline Rank & 2 & 3 & 1 \\
\hline
\end{tabular}

Table 3:_Surface Temp. Response Table for Means

\begin{tabular}{|l|l|l|l|}
\hline Level & RPM & FEED & D.O.C \\
\hline 1 & 33.20 & 31.65 & 33.50 \\
\hline 2 & 31.83 & 32.05 & 31.40 \\
\hline 3 & 31.63 & 32.98 & 31.42 \\
\hline 4 & 31.68 & 31.65 & 32.00 \\
\hline Delta & 1.58 & 1.33 & 2.10 \\
\hline Rank & 2 & 3 & 1 \\
\hline
\end{tabular}


This plot shows the variation of Surafce Temperature with change in three parameters: In the plots, the $\mathrm{x}$ axis indicates the value of each process parameter, $y-$ axis the response value (Temp.). Horizontal line indicates the mean value of the response. The main effects plots are used to determine the optimal design conditions to obtain the optimum Surface Temp. Main effects plots for Surface Temp. here are plotted between

1. Surface Temp. V/s Cutting speed

2. Surface Temp V/s Feed.

3. Surface Temp V/s Depth of cut

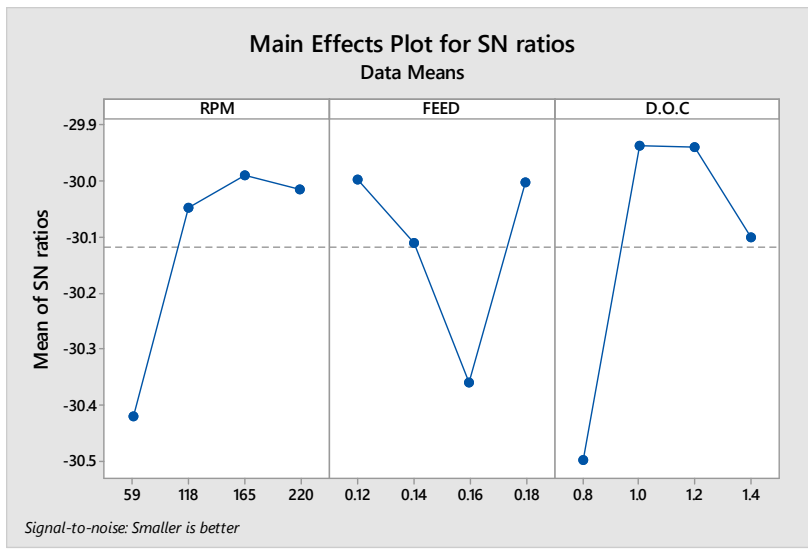

\section{Graph 1: Main effects of Plot for S/N Ratio Surface Temperature}

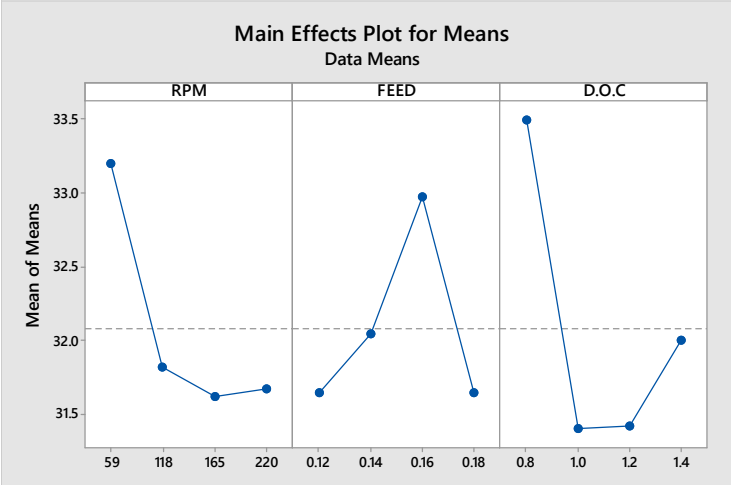

\section{Graph 2: Main effects of Plot for Means of Surface Temperature}

The effect of each parameter on the Surface Temp is plotted on the graph in form of lines .main effects plot for $\mathrm{S} / \mathrm{N}$ ratios it can be clearly seen that the Surface Temp with an increase in the values of cutting speed, and Surface Temp is minimum at the first level of feed $\&$ at second level of depth of cut.
Table 4: Analysis of Variance of Surface Temp. for $\mathrm{SN}$ ratios

\begin{tabular}{|c|c|c|c|c|c|c|}
\hline Source & DF & $\begin{array}{c}\text { Seq } \\
\text { SS }\end{array}$ & $\begin{array}{c}\text { Adj } \\
\text { SS }\end{array}$ & $\begin{array}{c}\text { Adj } \\
\text { MS }\end{array}$ & F & P \\
\hline RPM & 3 & 0.4947 & 0.4947 & 0.16490 & 5.60 & 0.036 \\
\hline FEED & 3 & 0.3450 & 0.3450 & 0.11502 & 3.91 & 0.073 \\
\hline D.O.C & 3 & 0.8376 & 0.8376 & 0.27919 & 9.49 & 0.011 \\
\hline $\begin{array}{c}\text { Residual } \\
\text { Error }\end{array}$ & 6 & 0.1766 & 0.1766 & 0.02943 & & \\
\hline Total & 15 & 1.8539 & & & & \\
\hline
\end{tabular}

Table 5:_Analysis of Variance of Surface Temp. for Means

\begin{tabular}{|l|l|l|l|l|l|}
\hline Source & DF & Seq SS & Adj MS & F & P \\
\hline RPM & 3 & 6.762 & 2.2540 & 5.59 & 0.036 \\
\hline FEED & 3 & 4.687 & 1.5623 & 3.88 & 0.074 \\
\hline D.O.C & 3 & 11.657 & 3.8856 & 9.64 & 0.010 \\
\hline $\begin{array}{l}\text { Residual } \\
\text { Error }\end{array}$ & 6 & 2.419 & 0.4031 & & \\
\hline \begin{tabular}{l} 
Total \\
\hline
\end{tabular} & 15 & 25.524 & & & \\
\hline
\end{tabular}

The following entities for the analysis of variance (ANOVA) have been calculated.

1. Sum of square (SS) for the general, group effects and residual effects.

2. Associated degree of freedom (df) with [n (factors)1]

3. Mean square (MS) (dividing SS by df)

4. F statistic (dividing MS of factors by MS of error)

\section{Conclusions and Scope for future work}

It is concluded that for Temperature to be minimum Cutting speed has to be at high level 4, Feed has to be at low level $1 \&$ D.O.C has to be at level 2 .

In future the experimentation can be done on other grades of stainless steel like SS 301L, SS 302HQ, SS 321 and SS 430 which are widely and commonly used in the industry. Further study could consider more factors (e.g. tool vibration, lubricant, etc.) in the 
research to see how the factors would affect material removal rate.

\section{REFERENCES}

1) Pal S. K. \& Chakraborty D., (2005), "Surface roughness prediction in turning using artificial neural network", Neural Computing \& Application, Volume14, pp. 319-324.

2) Singh H. \& Kumar P., (2006), “Optimizing Feed Force for Turned Parts through the Taguchi Technique", Sadhana, Volume 31, Number 6, pp.. 671-681. 58

3) Ahmed S. G., (2006), "Development of a Prediction Model for Surface Roughness in Finish Turning of Aluminium", Sudan Engineering Society Journal, Volume 52, Number 45, pp.. 1-5.

4) Abburi N. R. \& Dixit U. S., (2006), "A knowledge-based system for the prediction of surface roughness in turning process" Robotics \& Computer-Integrated Manufacturing, Volume 22, pp.. 363-372.

5) Zhong Z. W., Khoo L. P. \& Han S. T., (2006), "Prediction of surface roughness of turned surfaces using neural networks", International Journal of Advance Manufacturing Technology, Volume 28, pp.. 688-693.

6) Kumanan S., Saheb S. K. N. \& Jesuthanam C. P., (2006), "Prediction of Machining Forces using Neural Networks Trained by a Genetic Algorithm", Institution of Engineers (India) Journal, Volume 87, pp.. 11-15.

7) Mahmoud E. A. E. \& Abdelkarim H. A., (2006), "Optimum Cutting Parameters in Turning Operations using HSS Cutting Tool with 450 Approach Angle", Sudan Engineering Scoeiety Journal, Volume 53, Number 48, pp.. 25-30.

8) Doniavi A., Esk\&erzade M. \& Tahmsebian M., (2007), "Empirical Modeling of Surface Roughness in Turning Process of 1060 steel using Factorial Design Methodology", Journal of Applied Sciences, Volume 7, Number17, pp.. 2509-2513.

9) Kassab S. Y. \& Khoshnaw Y. K., (2007), "The Effect of Cutting Tool Vibration on Surface Roughness of Work piece in Dry Turning Operation", Engineering \& Technology, Volume 25, Number 7, pp.. 879-889.
10) Al-Ahmari A. M. A., (2007),'Predictive machinability models for a selected hard material in turning operations", Journal of Materials Processing Technology, Volume 59 190, pp.. 305-311.

11) Thamizhmanii S., Saparudin S. \& Hasan S., (2007), "Analysis of Surface Roughness by Using Taguchi Method", Achievements in Materials \& Manufacturing Engineering, Volume 20, Issue 12, pp.. 503-505.

12) Natarajan U., Arun P., Periasamy V. M., (2007), "On-line Tool Wear Monitoring in Turning by Hidden Markov Model (HMM)" Institution of Engineers (India) Journal (PR), Volume 87, pp.. 31-35.

13) Özel T. \& Karpat Y., (2005), "Predictive modeling of surface roughness \& tool wear in hard turning using regression \& neural networks", International Journal of Machine Tools \& Manufacture, Volume 45, pp.. 467-479. 